\title{
RESEARCH
}

Open Access

\section{The neovaginal microbiome of transgender women post-gender reassignment surgery}

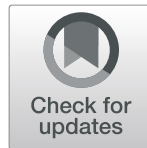

\author{
Kenzie D. Birse ${ }^{1,2+}$, Kateryna Kratzer ${ }^{1,2 \dagger}$, Christina Farr Zuend ${ }^{1,2}$, Sarah Mutch ${ }^{1,2}$, Laura Noël-Romas ${ }^{1,2}$, \\ Alana Lamont ${ }^{1,2}$, Max Abou' $^{1}$, Emilia Jalii ${ }^{3}$, Valdiléa Veloso ${ }^{3}$, Beatriz Grinsztejn ${ }^{3}$, Ruth Khalili Friedman ${ }^{3}$, \\ Kristina Broliden ${ }^{4}$, Frideborg Bradley ${ }^{4}$, Vanessa Poliquin ${ }^{5}$, Fan $\mathrm{Li}^{6}$, Carolyn Yanavich ${ }^{6}$, Adam Burgener ${ }^{1,2,4,5^{*+}+}$ and \\ Grace Aldrovandi ${ }^{*}+$
}

\begin{abstract}
Background: Gender reassignment surgery is a procedure some transgender women (TW) undergo for genderaffirming purposes. This often includes the construction of a neovagina using existing penile and scrotal tissue and/ or a sigmoid colon graft. There are limited data regarding the composition and function of the neovaginal microbiome representing a major gap in knowledge in neovaginal health.

Results: Metaproteomics was performed on secretions collected from the neovaginas $(n=5)$ and rectums $(n=7)$ of TW surgically reassigned via penile inversion/scrotal graft with $(n=1)$ or without $(n=4)$ a sigmoid colon graft extension and compared with secretions from cis vaginas $(n=32)$. We identified 541 unique bacterial proteins from 38 taxa. The most abundant taxa in the neovaginas were Porphyromonas (30.2\%), Peptostreptococcus (9.2\%), Prevotella (9.0\%), Mobiluncus (8.0\%), and Jonquetella (7.2\%), while cis vaginas were primarily Lactobacillus and Gardnerella. Rectal samples were mainly composed of Prevotella and Roseburia. Neovaginas (median Shannon's H index $=1.33)$ had higher alpha diversity compared to cis vaginas (Shannon's $H=0.35)(p=7.2 \mathrm{E}-3$, Mann-Whitney $U$ test) and were more similar to the non-Lactobacillus dominant/polymicrobial cis vaginas based on beta diversity (perMANOVA, $p=0.001, r^{2}=0.342$ ). In comparison to cis vaginas, toll-like receptor response, amino acid, and shortchain fatty acid metabolic pathways were increased $(p<0.01)$, while keratinization and cornification proteins were decreased $(p<0.001)$ in the neovaginal proteome.

Conclusions: Penile skin-lined neovaginas have diverse, polymicrobial communities that show similarities in composition to uncircumcised penises and host responses to cis vaginas with bacterial vaginosis (BV) including increased immune activation pathways and decreased epithelial barrier function. Developing a better understanding of microbiome-associated inflammation in the neovaginal environment will be important for improving our knowledge of neovaginal health.
\end{abstract}

Keywords: Transgender women, Neovagina, Gender reassignment surgery, Microbiome, Metaproteomics

\footnotetext{
*Correspondence: adam.burgener@umanitoba.ca;

GAldrovandi@mednet.ucla.edu

${ }^{\dagger}$ Kenzie D. Birse, Kateryna Kratzer, Adam Burgener and Grace Aldrovandi contributed equally to this work.

${ }^{1}$ National HIV and Retrovirology Labs, JC Wilt Infectious Disease Research

Centre, Public Health Agency of Canada, 745 Logan Ave, Winnipeg, MB R3E

3 L5, Canada

${ }^{6}$ University of California, Los Angeles, CA, USA

Full list of author information is available at the end of the article
}

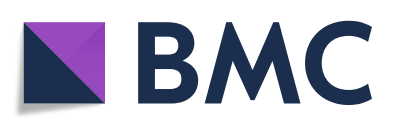

(- The Author(s). 2020 Open Access This article is licensed under a Creative Commons Attribution 4.0 International License, which permits use, sharing, adaptation, distribution and reproduction in any medium or format, as long as you give appropriate credit to the original author(s) and the source, provide a link to the Creative Commons licence, and indicate if changes were made. The images or other third party material in this article are included in the article's Creative Commons licence, unless indicated otherwise in a credit line to the material. If material is not included in the article's Creative Commons licence and your intended use is not permitted by statutory regulation or exceeds the permitted use, you will need to obtain permission directly from the copyright holder. To view a copy of this licence, visit http://creativecommons.org/licenses/by/4.0/. The Creative Commons Public Domain Dedication waiver (http://creativecommons.org/publicdomain/zero/1.0/) applies to the data made available in this article, unless otherwise stated in a credit line to the data. 


\section{Introduction}

Transgender is a term used to define people whose gender identity is different from their assigned sex at birth [1]. Many transgender women (TW), defined here as people assigned as male at birth who identify as female, undergo medical interventions such as feminizing hormone therapy and gender reassignment surgery (GRS) for gender affirmation purposes [2]. GRS generally includes neovaginoplasty, during which a neovagina is created through penile inversion, scrotal grafts, sigmoid colon grafts, and/or a combination thereof [3].

There are scarce data about the environment of the neovagina particularly at the molecular and microbial level. For cisgender women (CW), i.e., those assigned as female at birth, it is well understood that optimal vaginal microbiota include Lactobacillus species. Meanwhile, non-optimal microbial communities in the cis vagina such as those containing Gardnerella vaginalis, Atopobium, Prevotella, Mobiluncus, and other anaerobic species are often higher in diversity and associate with a condition known as bacterial vaginosis (BV). BV or anaerobic dysbiosis has been linked to increased genital tract inflammation and an increased risk of STI acquisition in CW as well as in uncircumcised men [4-7]. However, limited molecular sequencing studies have been conducted on neovaginas for the purposes of defining the microbiome $[8,9]$. To address this gap, we chose to investigate the neovaginal microbiome using a metaproteomics technique [10]. The objectives of this study were to map and characterize the microbial composition and function of neovaginal and rectal secretions from TW and compare them with vaginal secretions from CW and to assess relationships between microbial communities measured and host immune pathways.

\section{Results}

\section{Demographic and clinical characteristics of study participants}

We examined rectal and neovaginal secretions from TW $(n=9)$ and compared them against vaginal secretions from CW $(n=30)$. We excluded participants without measurable bacterial protein levels. Five out of the nine (56\%) neovaginal samples and seven out of the nine (78\%) rectal samples and all cis vaginal samples had measurable bacterial protein levels and remained in the analysis. Age, GRS methods, feminizing hormone therapy, sexually transmitted infections (STI), and sexual behavior data for the TW and CW with measurable neovaginal and vaginal microbiome data are described in Table 1 . CW were younger (median age $=31$ ) than TW $($ median age $=48)(p=0.058$, Mann-Whitney $U$ test, Table 1). The median time elapsed since last GRS was 9.5 years (range $3.5-34$ years).

\section{Neovaginal secretions contain diverse communities of anaerobic bacteria}

Mass spectrometry analysis identified a total of 541 unique bacterial proteins from 38 genera belonging to 7 different phyla: Actinobacteria, Bacteroidetes, Firmicutes, Fusobacteria, Proteobacteria, Synergistetes, and Tenericutes. We identified on average 8 species per neovaginal sample (range 2-17), 6 species per rectal sample (range 1-18), and 5 species per cis vaginal sample (range 1-14). On average, the most prevalent taxa by protein abundance in the neovaginal samples were Porphyromonas (30.2\%), Peptostreptococcus (9.2\%), Prevotella (9.0\%), and Mobiluncus $(8.0 \%)$, with a large proportion undistinguishable (16.9\%) (median bacterial spectral count $=63$, range $=$ 14.5-177.9). In rectal secretions, the most abundant bacterial taxa were Prevotella (52.0\%), Roseburia (20.7\%), Firmicutes (6.8\%), Eubacterium (3.6\%), and Lysinibacillus (3.1\%) (median bacterial spectral count $=12.13$, range $=$ 7.5-435.7). In cis vaginal secretions, the most abundant taxa were Lactobacillus (64.8\%), Gardnerella (18.2\%), Lysinibacillus (8.2\%), and Prevotella (2.7\%) (median bacterial spectral count $=113.2$, range $=4.1-456.3$ ) (Fig. 1a). $16 \mathrm{~S}$ rRNA gene analysis also detected many of these major taxa identified via metaproteomic analysis as well as many other taxa in neovaginal, rectal, and cis vaginal samples, respectively (Supplemental Figures 1, 2 and 3). Total bacterial signal did not significantly differ based on sample type ( $p=0.34$, Kruskal-Wallis).

Hierarchical clustering of individual profiles revealed 3 main branches based on bacterial protein composition (Fig. 1b). Branch 1 included 5 rectal samples, and 1 cis vaginal sample dominated by Prevotella or Roseburia. Branch 2 and 3a were composed entirely of cis vaginal samples who were dominated by Lactobacillus or Gardnerella, respectively. Branch $3 \mathrm{~b}$ included all neovaginal samples $(n=5)$ as well as 3 cis vaginal and 2 rectal samples. Branch $3 \mathrm{~b}$ had significantly higher alpha diversity based on Shannon's $H$ diversity than branch 1,2 , and $3 \mathrm{~A}(2.77,5.27$, and 2.9 fold changes, respectively; Shannon's $H$ index, $p=$ 0.0005, Kruskal-Wallis). Neovaginal samples had higher alpha diversity (Shannon $H$ index median = 1.33) than cis vaginal samples (Shannon $H$ median = 0.35) ( $p=0.0072$, Mann-Whitney $U$ test) when examined separately. Indeed, neovaginas grouped more closely with non-Lactobacillus dominant/polymicrobial (< $50 \%$ Lactobacillus proteins contribute to the microbial profile) than cis vaginas when Bray-Curtis dissimilarity distances were examined (Fig. 2). Variation in bacterial community composition between individuals can be attributed to sample type ( $p=0.001$, $r^{2}=0.13$, perMANOVA) and Lactobacillus levels ( $p=$ $0.001, r^{2}=0.21$ perMANOVA). $16 \mathrm{~S}$ rRNA gene profiling also revealed similarities between the neovaginal 
Table 1 Demographic, clinical, and behavioral data of study participants with microbiome data

\begin{tabular}{|c|c|c|c|c|}
\hline Variable & Variable category & $\begin{array}{l}\text { Transgender } \\
\text { women-neovaginal } \\
\text { samples }(n=5)^{\mathrm{a}}\end{array}$ & $\begin{array}{l}\text { Transgender } \\
\text { women-rectal } \\
\text { samples }(n=7)^{\mathrm{a}}\end{array}$ & $\begin{array}{l}\text { Cisgender } \\
\text { women—vaginal } \\
\text { samples }(n=30)^{\mathrm{b}}\end{array}$ \\
\hline Age (median, range) & & $48(28-57)$ & $48(35-57)$ & $31(19-55)$ \\
\hline $\begin{array}{l}\text { Time since first neovaginoplasty } \\
\text { (median, range) }\end{array}$ & Years & $9.5(3.7-35.7)$ & $10.9(5.1-35.7)$ & NA \\
\hline $\begin{array}{l}\text { Time since most recent neovaginoplasty } \\
\text { (median, range) }\end{array}$ & Years & $9.5(3.5-34)$ & $9.5(1.5-34)$ & NA \\
\hline \multirow[t]{2}{*}{ Surgery method—all techniques $(n, \%)$} & Penile inversion, scrotal cutaneous graft & $4(80)$ & $4(57)$ & \multirow[t]{2}{*}{ NA } \\
\hline & $\begin{array}{l}\text { Penile inversion, scrotal cutaneous graft } \\
\text { with sigmoid colon extension }\end{array}$ & $1(20)$ & $3(43)$ & \\
\hline Total number of surgeries (median, range) ${ }^{c}$ & & $1(1-4)$ & $2(1-6)$ & NA \\
\hline Vaginal complaints $(n, \%)^{d}$ & & $2(40)$ & $3(43)$ & $13(43)$ \\
\hline Number who practice vaginal washing $(n, \%)$ & & $1(20)$ & $1(20)$ & $1(3.3)$ \\
\hline \multirow[t]{3}{*}{ Hormone therapy $(n, \%)^{\mathrm{e}}$} & $\begin{array}{l}\text { Estrogen therapy/hormonal } \\
\text { contraception }\end{array}$ & $3(60)$ & $5(71)$ & $11(37)$ \\
\hline & $\begin{array}{l}\text { Not currently on therapy/hormonal } \\
\text { contraception }\end{array}$ & $1(20)$ & $1(14)$ & $16(53)$ \\
\hline & Unknown & $1(20)$ & $1(14)$ & $3(10)$ \\
\hline \multirow[t]{8}{*}{$\operatorname{STI}(n, \%)^{f}$} & Hepatitis B & $4(80)$ & $5(71)$ & $\begin{array}{l}\text { Data not } \\
\text { collected }\end{array}$ \\
\hline & Hepatitis C & $0(0)$ & $0(0)$ & $\begin{array}{l}\text { Data not } \\
\text { collected }\end{array}$ \\
\hline & Active syphilis & $0(0)$ & $1(14)$ & $\begin{array}{l}\text { Data not } \\
\text { collected }\end{array}$ \\
\hline & Anal chlamydia & $0(0)$ & $2(29)$ & $\begin{array}{l}\text { Data not } \\
\text { collected }\end{array}$ \\
\hline & Vaginal chlamydia & $0(0)$ & $1(14)$ & $1(3.3)$ \\
\hline & Anal gonorrhea & $1(20)$ & $0(0)$ & $\begin{array}{l}\text { Data not } \\
\text { collected }\end{array}$ \\
\hline & Vaginal gonorrhea & $0(0)$ & $0(0)$ & 0 \\
\hline & HIV & $0(0)$ & $0(0)$ & $2(6.7)$ \\
\hline \multirow{3}{*}{$\begin{array}{l}\text { Sexually active in } 30 \text { days prior } \\
\text { to sample collection }(n, \%)^{9}\end{array}$} & Reported receptive anal sex & $1(20)$ & $3(43)$ & NA \\
\hline & Reported receptive neovaginal sex & $2(40)$ & $4(57)$ & NA \\
\hline & Reported cis vaginal sex & NA & NA & $19(63)$ \\
\hline Condom use in the last 30 days $(n, \%)^{\mathrm{h}}$ & & $0(0)$ & $0(0)$ & $7(23)$ \\
\hline $\begin{array}{l}\text { Number of sexual partners in the } \\
\text { last } 30 \text { days (median, range) }\end{array}$ & & $1(0-1)$ & $1(0-1)$ & $\begin{array}{l}\text { Data not } \\
\text { collected }\end{array}$ \\
\hline Applied a chemical substance $(n, \%)^{i}$ & & $2(40)$ & $2(29)$ & $\begin{array}{l}\text { Data not } \\
\text { collected }\end{array}$ \\
\hline Used sex toy in vagina $(n, \%)$ & & $2(40)$ & $1(14)$ & $\begin{array}{l}\text { Data not } \\
\text { collected }\end{array}$ \\
\hline
\end{tabular}

${ }^{\mathrm{a} N i n e}$ transgender women (TW) had both neovaginal and rectal samples collected for metaproteomics, but only 5 neovaginal samples and 7 rectal samples had bacterial proteins detected

${ }^{\mathrm{b}} \mathrm{A}$ total of 32 samples from 30 cisgender women (CW) were collected. Two samples were longitudinal from the same Swedish participants

${ }^{c}$ Reasons for re-operation included stenosis, procedural complications, dissatisfaction with external appearance, anorgasmia, and sexual mismatch

${ }^{d}$ Vaginal complaints included spontaneous pain, pain during intercourse, spontaneous bleeding, fetid odor and/or vaginal depth amongst TW, and vaginal discomfort, discharge, itching, pain, bleeding, and odor amongst CW

${ }^{e} \mathrm{CW}$ reported using either oral contraceptive pills, injectable contraception, vaginal ring contraception, or a hormonal intrauterine device

${ }^{f}$ All STIs were tested for at the time of sample collection. Hepatitis B seropositivity represented past exposure

Includes instances of neovaginal and/or anal intercourse for TW and penetrative vaginal intercourse for CW

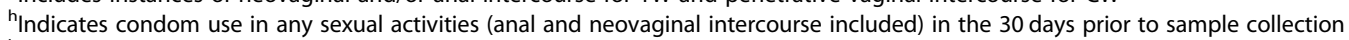

'Chemical substances included lubricants, soap, and/or douche 

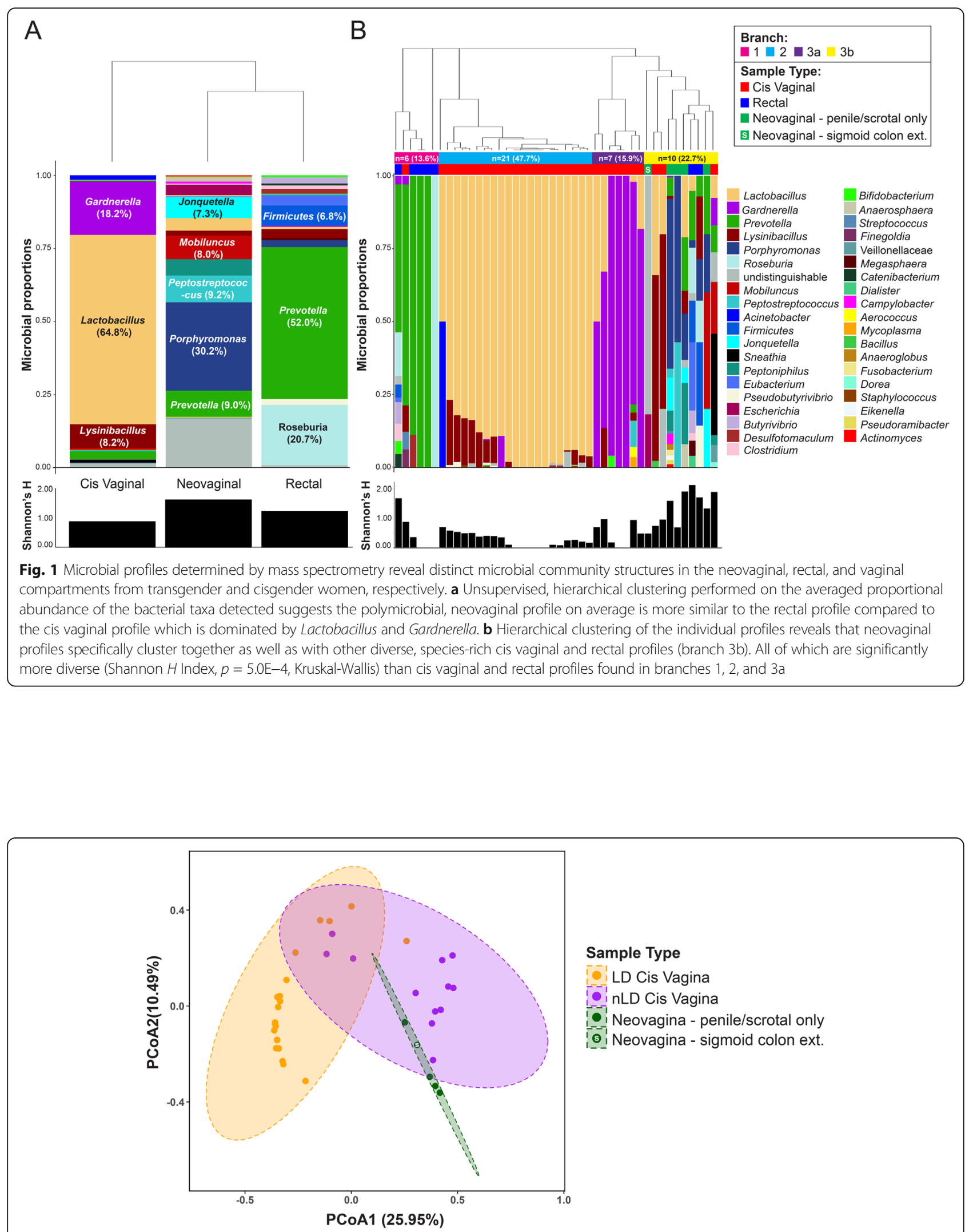

Sample Type

LD Cis Vagina

nLD Cis Vagina

Neovagina - penile/scrotal only

Neovagina - sigmoid colon ext.

Fig. 2 Principal coordinate analysis demonstrates that neovaginal bacterial composition is more similar to that of non-Lactobacillus-dominant $(n L D) /$ polymicrobial than Lactobacillus-dominant (LD) cis vaginas based on Bray-Curtis dissimilarity distances 
and non-Lactobacillus dominant/polymicrobial cis vaginal bacterial communities (Supplemental Figures 1 and 2) highlighted by the increased abundance of Prevotella and increased overall diversity.

Proteins annotated to Jonquetella anthropi, the only bacteria identified belonging to the phylum Synergistetes, were uniquely identified in $60 \%$ of neovaginal samples. $16 \mathrm{~S}$ rRNA genes belonging to family Synergistaceae were detected in $80 \%$ the neovaginal samples. Other unique taxa identified in at least one neovaginal sample included various Proteobacteria (Escherichia, Campylobacter, Eikenella), Firmicutes (Anaerosphaera, Anaeroglobus, Pseudoramibacter), Fusobacteria (Fusobacterium), and Actinobacteria (Actinomyces). Interestingly, the one neovaginal sample that had a sigmoid colon graft for neovaginal extension purposes had a microbiome that appeared more gut-like such that Bacteroidaceae and Enterobacteriaceae were the main taxa detected via $16 \mathrm{~S}$ rRNA gene sequencing. This was partially confirmed via metaproteomics as there were Escherichia proteins detected as well (Supplemental Figure 1). This participant's matching rectal sample (R6) was also composed of elevated levels of Bacteroidaceae (41\%) as measured by $16 \mathrm{~S}$ rRNA gene sequencing (Supplemental Figure 3).

A subset of the samples $(n=4)$ included in this study had matched neovaginal and rectal secretions collected (Supplemental Figure 4A). Principal coordinate analysis highlighted the differences in microbial composition based on bacterial proteins that exist between each of the rectal-neovaginal sample pairs based on beta diversity (Bray-Curtis distances) (Supplemental Figure 4B). Variation in bacterial community composition between rectal and neovaginal samples can be attributed to sample type $\left(p=0.014, r^{2}=0.24\right.$, perMANOVA $)$ and Roseburia levels $\left(p=0.02, r^{2}=0.20\right.$, perMANOVA).

\section{Microbial functional differences exist between neovaginal and cis vaginal samples}

Of the 541 bacterial proteins identified, 377 (70\%) were successfully assigned functions from the KEGG Pathway database. The top five most abundant broad, B-level functions in neovaginal samples included energy metabolism (29.8\%), carbohydrate metabolism (23.2\%), amino acid metabolism (17.8\%), metabolism of cofactors and vitamins (9.3\%), and signal transduction (7.6\%). The top B-level functions in cis vaginal samples were carbohydrate metabolism (37.5\%), energy metabolism (17.5\%), signal transduction (8.2\%), metabolism of cofactors and vitamins (6.1\%), and membrane transport (5.1\%) (Supplemental Figure 5). Upon further evaluation of more specific functional categories (KEGG ko level), vitamin B6 metabolism via phosphoserine aminotransferase from Poryphromonas and various forms of amino acid and fatty acid metabolism were uniquely associated with neovaginal samples (Supplemental Table 1).

\section{The neovagina associates with increased immune activation and decreased barrier function pathways}

To explore host immunity differences between neovaginas and cis vaginas, we performed differential protein expression analysis; 158 (15.1\%) proteins were significantly different between neovaginas and cis vaginas $(p<$ 0.05 , Mann-Whitney $U$ test, Supplemental Table 2). Of those 158, 68 met the $80 \%$ power restriction based on an effect size of 2.7-fold difference. Principal component analysis and hierarchical clustering highlighted how the abundance of these proteins differs between neovaginal and cis vaginal samples (Fig. 3).

Within the hierarchical clustering analysis, two major branches were observed (Fig. 3b). Branch 1 included proteins with known functions in the citrate cycle $(8$ proteins, $q=8.8 \mathrm{E} 10)$, various forms amino acid metabolism (arginine and proline (6 proteins, $q=1.84 \mathrm{E}-5$ ); valine, leucine and isoleucine (5 proteins, $q=1.4 \mathrm{E}-4$ ), histidine (4 proteins, $q=1.4 \mathrm{E}-4)$; alanine, aspartate, glutamate (4 proteins, 4.73E-4); tyrosine ( $n=4$, 3.99E-4); phenylalanine (3 proteins, $q=4.82 \mathrm{E}-4$ ); and lysine degradation (3 proteins, $q=1.78 \mathrm{E}-3)$ ), glyoxylate metabolism (4 proteins, $q=3.16 \mathrm{E}-4)$, Fc gamma R-mediated phagocytosis ( 5 proteins, $q=1.05 \mathrm{E}-3$ ), toll-like receptor (TLR) responses (TLR JNK (3 proteins, $q=1.73 \mathrm{E}-2$ ), TLR p38 (3 proteins, $q=1.74 \mathrm{E}-2$ ), TLR NFKB (3 proteins, $q=1.92 \mathrm{E}-2)$, bacterial invasion of epithelial cells (3 proteins, $q=2.13 \mathrm{E}-2$ ), and short chain fatty acid metabolism (butanoate (2 proteins, $q=1.55 \mathrm{E} 02$ ), proponaote ( 2 proteins, $q=2.22 \mathrm{E}-2)$, all of which were increased in the neovagina (Supplemental Table 3). There were also decreased levels of proteins associated with keratinization (19 proteins, $q=1.22 \mathrm{E}-21$ ), cornified envelope formation processes (10 proteins, $q=7.99 \mathrm{E}$ $-11)$, apoptotic cleavage of cell adhesion proteins $(n=3$, $q=4.20 \mathrm{E}-4)$, the estrogen signaling pathway (4 proteins, $q=2.18 \mathrm{E}-2)$, and the innate immune system (15 proteins, $q=2.44 \mathrm{E}-3$ ) including various antimicrobial $/ \mathrm{com}$ plement (CAMP, CFH, LCN2, CRISP3, C6) and cell redox homeostasis proteins (TXN, QSOX1) in the neovagina (Supplemental Table 4). Many of these same functions were correlated with alpha diversity (Shannon's $H$ index) (Supplemental Table 5, 6 and 7).

Furthermore, we performed protein set enrichment analysis comparing our data set against pre-defined protein sets from cervical immune cells. The protein set that was the most enriched and overlapped with the proteins found to decrease in the neovaginal compartment relative to the cis vaginal compartment were from CD4+CD38+HLADR+ T 
A

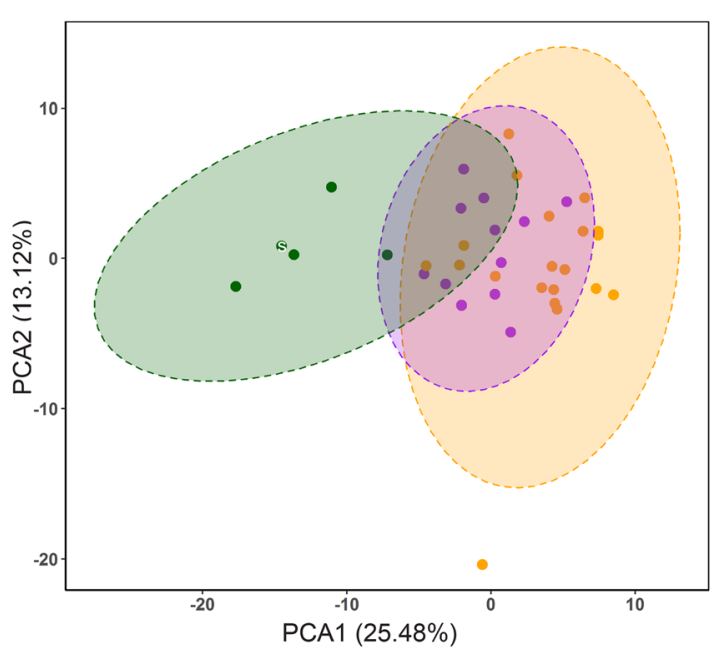

\section{Sample Type}

- LD Cis Vaginal

nLD Cis Vaginal

Neovaginal - penile/scrotal only

- Neovaginal - sigmoid colon ext.

B
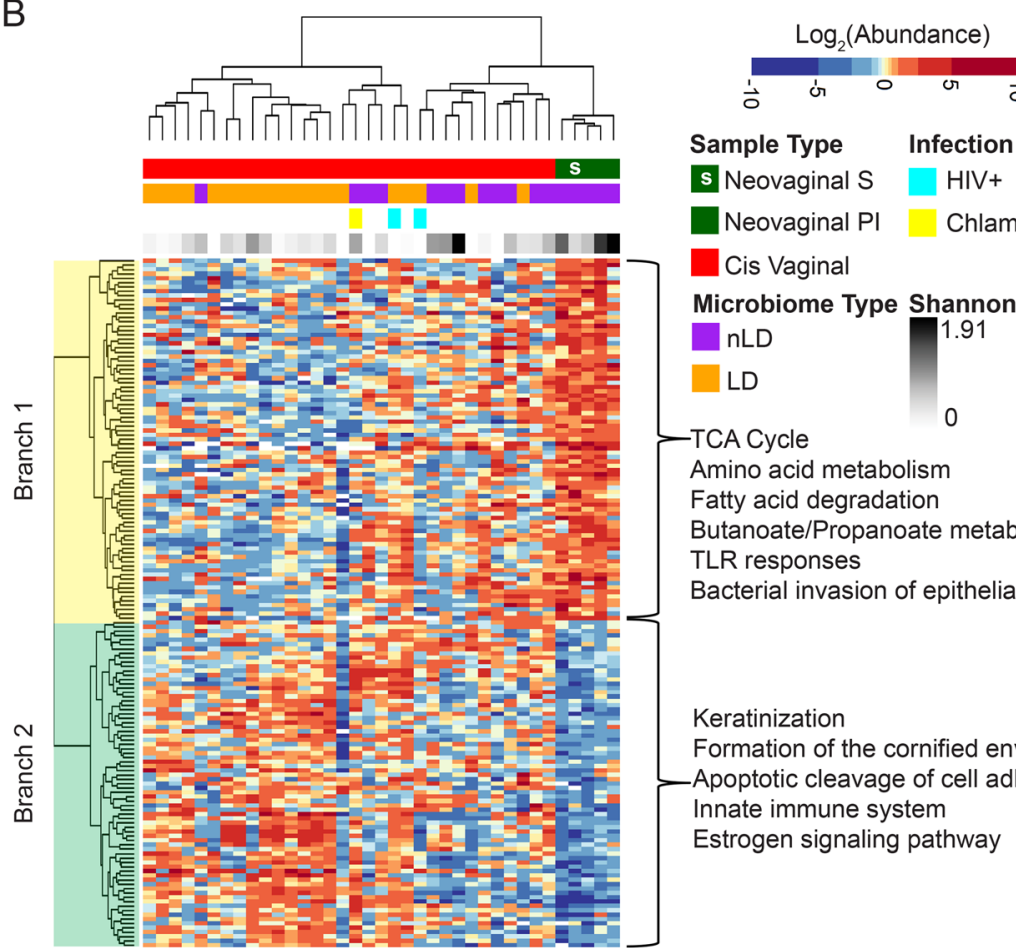

Sample Type Infection

s Neovaginal S HIV+

Neovaginal PI Chlamydia+

Cis Vaginal

Microbiome Type Shannon H Index

nLD

LD

TCA Cycle

Amino acid metabolism

Fatty acid degradation

Butanoate/Propanoate metabolism

TLR responses

Bacterial invasion of epithelial cells

Keratinization

Formation of the cornified envelope

Apoptotic cleavage of cell adhesion proteins

Innate immune system

Estrogen signaling pathway

Fig. 3 Increased immune activation and decreased keratinization and barrier pathways are associated with the neovagina. a Neovaginal samples have an overall unique host proteome signature compared to cis vaginal samples based on variation decomposition via principal coordinate analysis. $\mathbf{b}$ Hierarchical clustering of human proteins differentially abundant between neovaginas and cis vaginas ( $p<0.05$, Mann-Whitney $U$ test). Neovaginas had increased signatures of immune activation and bacterial invasion and decreased barrier function and estrogen signaling pathways ( $q<0.05$, ConsensusPathDB). (LD = Lactobacillus dominant, $\mathrm{nLD}=$ non-Lactobacillus dominant, neovaginal $\mathrm{S}=$ sigmoid colon graft extension, neovaginal PI = penile inversion/scrotal graft only)

cells (normalized enrichment score $=-2.01, \mathrm{FDR} q$ value $=$ 1.16E-3) (Supplemental Figure 6, Supplemental Table 8).

\section{Discussion}

Anaerobic bacterial species dominated the neovaginal microbiome. The neovaginal microbial profiles identified in this study overlap with what has been seen in previous penile skin-lined neovaginal studies as well as uncircumcised penile studies including elevated levels of Prevotella, Porphyromonas, and Peptoniphilus (Clostridiales Family XI) [7, $8,11-15]$. Indeed, the bacterial composition of penile skinlined neovaginas resembled those of uncircumcised penises with penile community state types (CST) known to be abundant with BV-associated bacteria [14].

Despite the great deal of consistency of taxa observed in our study and others, several unique taxa were also 
identified: Eikenella, Anaeroglobus, Anaerosphaera, and Pseudoramibacter. Bacteria identified in the neovagina may represent bacteria that were seeded by unique routes of transmission. For instance, Eikenella corrodens is a commensal bacteria found in the mouth. Oralgenital contact has been suggested as a possible route of transmission of these bacteria to the genital tract [16]. Anaeroglobus geminatusa, Pseudoramibacter alactolyticus, Campylobacter ureolyticus, Fusobacterium nucleatum, and Actinomyces have been described as putative pathogens also found in the oral cavity associated with periodontitis and endodontic infections [17-21]. The presence of oral bacteria in the neovaginal compartment could suggest oral-genital bacterial transmission. Jonquetella anthropi has been detected on the scrotum and penis and has also been described as an opportunistic pathogen associated with soft tissue infections [7, 22, 23]. Taxa belonging to the phylum Synergistetes have been detected from healthy cis vaginas, although we did not see any detected in the cis vaginal samples analyzed in our study [22]. Due to the detection of J. anthropi from scrotal/penile samples in other studies, and the fact that the penile inversion/scrotal graft surgical method was the main surgical method used on the TW in this study, there may have been carry over or seeding of these microbiota from the original penis and/or scrotum into the neovagina. Indeed, 3 out of the 4 participants and 4 out of 4 participants who had penile inversion/scrotal graft neovaginoplasty surgery method conducted without a sigmoid colon graft had detectable J. anthropi proteins and had measurable Synergistaceae 16S rRNA gene sequences, respectively, in their neovaginal samples. Furthermore, the one neovaginal sample that had a sigmoid colon graft in addition to the penile inversion/scrotal graft surgical method had a microbiome that appeared more gut-like as Bacteroidaceae and Enterobacteriaceae were the main taxa dominating its microbial profile. This finding provides further evidence that the organs used to generate and/or modify the neovagina represent major sources of bacterial transmission or origination that may contribute to the neovaginal microbiome.

Some studies suggest that the vaginal compartment is seeded by bacteria found in the rectal compartment [9]. We found very little bacterial protein-based compositional similarity between matching neovaginal and rectal profiles based on bacterial proteins measured, although we were underpowered to properly evaluate this comparison. The rectal microbial profiles observed in our study were similar to those of other studies particularly those that examined rectal/anal microbiomes of $\mathrm{CW}$ as well as men who have sex with men where Prevotella and Bacteroides were most abundant [24-26].

Various taxa that are associated with BV in CW were detected in the neovagina, including elevated levels of Prevotella, Mobiluncus, Porphyromonas, and Peptostreptococcus
[27]. Neovaginas also had similar host responses to cis vaginas with BV such that we observed increased immune activation signatures including increased amino acid metabolism, short-chain fatty acid metabolism, TLR responses, and bacterial invasion/phagocytosis, as well as decreased signatures of barrier and innate immune function [28-30]. Decreased levels of particular antimicrobial and/or defense proteins such as cathelicidin (CAMP) and lipocalin-2 (LCN2) may hinder appropriate immune responses to non-optimal bacteria [31, 32]. Decreases in LCN2 may lead to increased bacteria-driven inflammation as this protein has been shown to limit inflammation by restricting bacterial access to iron [33]. Increased amino acid metabolism, particularly the degradation of isoleucine, leucine, and valine, has been linked with antimicrobial protein expression including beta-defensins and mucosal barrier function [34, 35]. Therefore, a lack of these amino acids or amino acid starvation could impair barrier function. This has also been shown to trigger inflammation and $\mathrm{T}$ helper 17 cell responses [36, 37]. Furthermore, bacterial vitamin B6 metabolism, a bacterial function uniquely associated with neovaginas in our study, may also be linked to increased host inflammation and hindered immune responses as vitamin B6 levels have been shown to be inversely correlated with various proinflammatory markers. A deficiency in vitamin B6 is associated with reduced lymphocyte proliferation, $\mathrm{T}$ cellmediated cytotoxicity, and antibody production [38, 39]. We also found that neovaginal host signatures overlapped with signatures associated with elevated, activated CD4+ $\mathrm{T}$ cell levels in the female genital tract providing further evidence of increased immune activation signatures are being detected within the neovagina. Overall, these data suggest that neovaginas are similar to polymicrobial or BV-like cis vaginas based on the bacterial composition, bacterial function, and the corresponding host immune activation and barrier dysfunction profiles.

Neovaginas generated from penile and scrotal skin, which are known to express estrogen receptors, may also have an intrinsic pre-disposition to decreased barrier protein expression due to low estrogen levels relative to the cis vagina [40, 41]. Indeed, we found estrogenregulated keratins at lower levels in the neovagina as well as a number of cornified envelope proteins. The cornified envelope, as well as the corneodesmosomes found within, is critical to maintaining barrier integrity in tissues that experience mechanical stress such as the neovaginal or vaginal skin [42], and if these are weakened, neovaginas may be more likely to experience tears and/or damage and have limitations to their wound healing potential [43-45]. It is also well understood that estrogen promotes keratinization and barrier integrity in the vagina of animal models as well as in the inner foreskin in humans, and a lack of estrogen or its receptors 
results in a loss of the cornified layer [46-48]. Of the 5 neovaginal samples included in our analysis, three reported taking estrogen transdermally; therefore, it is possible our observations could be related to a lack of intrinsic and/or pharmaceutically delivered estrogen.

While there was considerable overlap, we observed different bacterial information from 16S rRNA gene sequencing and mass spectrometry-based proteomics. This is not unexpected as these two methodologies measure different components of the microbiome. Proteomic data better reflects the metabolic state of a bacterium which may be dependent upon many factors including the growth state, nutrient availability, and composition of the neighboring microbiota [49-51]. 16S rRNA gene data provides more sensitive data on bacterial composition, but does not provide information on bacterial activity. Therefore, it is not unexpected to observe differences in the proteomic and genomic data in this study.

Limitations exist in this study including its small sample size and post hoc study design. Four of the TW included in this study had the penile inversion/scrotal graft surgical method used for their neovaginoplasties, and one TW had the penile inversion/scrotal graft method with a sigmoid colon graft extension. Future studies with larger sample sizes will be required to better compare the impact of surgical method (i.e., penile inversion versus sigmoid colon grafts) on the microbiome. Further to this, future studies should include uncircumsised penile samples as a comparator to penile skin-lined neovaginal samples. Another limitation in our study was that the CW were not from the same geographic location as the TW and therefore may introduce underlying variation between study groups. There are a few methodological limitations in our study that are important to note. Shotgun proteomics is less sensitive than other sequencing methods such as $16 \mathrm{~S}$ rRNA sequencing and metagenomics, and therefore, fewer bacterial species were detected by metaproteomics. The $16 \mathrm{~S}$ rRNA gene sequencing methods used on CW and TW samples were different (V3-V4 vs V4 regions, respectively), as the CW data were originally generated for an independent study. Utilizing different regions of the 16S rRNA gene can impact which bacteria are preferentially amplified, and this represents a limitation to this study. Furthermore, the CW and TW 16S rRNA gene data were each processed using different bioinformatics pipelines, which could also introduce biases in each data set. Nevertheless, we do not expect these to be major contributing factors to the observations in this study. Despite these limitations, this is the first study to evaluate the microbiome of the neovagina using a metaproteomics technique where both bacterial composition and function can be described and related to host responses.

\section{Conclusions}

This study identified unique bacteria in the neovaginal compartment which may have been transmitted via the oral-genital route and/or may represent bacteria originally associated with the organs used to generate and/or modify the neovagina. This study corroborates previous neovaginal studies identifying neovaginas with diverse, polymicrobial communities that elicit similar host responses to cis vaginas with BV. Increased immune activation and reduced barrier protein signatures detected within the neovaginal compartment, whether caused by the bacteria present or an intrinsic lack or insufficient level of pharmaceutically delivered estrogen, are important findings that increase our understanding of the physiology of the neovagina.

\section{Methods}

\section{Study populations and ethics statement}

This is a cross-sectional study that evaluated Brazilian, TW recruited at the LaPClin-AIDS Clinical Research Laboratory of the National Institute of Infectious Diseases Evandro Chagas (INI), at Oswaldo Cruz Foundation (FIOCRUZ) in Rio de Janeiro, Brazil, and CW from Canada and Sweden. All TW were over the age of 18 and were tested for STIs including HIV, chlamydia, gonorrhea, syphilis, and hepatitis B and C. CW were also over the age of 18 , not pregnant, and were tested for HIV, chlamydia, and gonorrhea. Swedish participants included in our CW control group were from a low-risk cohort not taking any form of hormonal contraception. Canadian participants included in our CW control group were from a higher-risk cohort of women experiencing negative reproductive health outcomes including vaginal symptoms and/or HIV/STI infections. Women whose samples had no measurable bacterial protein levels were excluded. The study was approved by the Research Ethics Committee at the INI-FIOCRUZ, the Research Ethics Board of the University of Manitoba, and the Stockholm Regional Ethics Board. Written informed consent was obtained from all study participants.

\section{Sample collection}

Secretions were collected by swabbing the neovaginal and rectal compartments from TW who had undergone GRS. Cervicovaginal secretions were collected from CW via swab or cervicovaginal lavage. Secretions from TW were placed in cryotubes of $500 \mu \mathrm{L}$ Allprotect (Qiagen, Valencia, CA) and then frozen at $-80^{\circ} \mathrm{C}$. Secretions from $\mathrm{CW}$ were frozen at $-80^{\circ} \mathrm{C}$ shortly after collection.

\section{Sample preparation for mass spectrometry}

Swabs were centrifuged to remove excess Allprotect. Swabs were eluted with phosphate-buffered saline $(\mathrm{pH}$ $7.0)$ at $4{ }^{\circ} \mathrm{C}$. Eluates were centrifuged to remove cellular 
debris and stored at $-80^{\circ} \mathrm{C}$. Equal volumes and/or concentrations of each sample were digested with trypsin and analyzed by tandem mass spectrometry as described by Birse et al. [64]. Briefly, samples were denatured with urea, reduced with diothiothreitol, alkylated with iodoacetamide, and digested with trypsin into peptides. Peptides were cleaned of salt and detergents by reversephase liquid chromatography (LC) using a step-function gradient. Cleaned peptides were quantified using LavaPep's Fluorescent Peptide and Protein Quantification Kit (Gel Company, CA, USA) according to the manufacturer's protocol.

\section{Mass spectrometry analysis}

One microgram of peptide per sample was re-suspended in $2 \%$ acetonitrile, $0.1 \%$ formic acid, and injected into a nano-flow LC system (Easy nLC, Thermo Fisher, MA, USA) connected inline to a $\mathrm{Q}$ Exactive Quadrupole Orbitrap mass spectrometer (Thermo Fisher, MA, USA). The Q Exactive mass spectrometer (MS) used the following method: a $50-\mathrm{cm}$ long, $2.0-\mu \mathrm{m}$ particle-sized Easy-Spray C-18 column (Thermo Fisher, MA, USA) was used for peptide separation. The elution gradient was from $98 \%$ buffer A to $30 \%$ buffer B in $200 \mathrm{~min}$ at a constant flow rate of $200 \mathrm{~nL} / \mathrm{min}$. MS spectra were acquired on the Orbitrap analyzer at 70,000 resolution at $200 \mathrm{~m} / \mathrm{z}$. After each MS spectrum and automatic selection, the 15 most intense precursor ions were selected from fragmentation by high collision dissociation, at $28 \%$ normalized collision energy, and were acquired in the Orbitrap analyzer at 17,500 resolution at $200 \mathrm{~m} / \mathrm{z}$.

Bacterial peptide identity searching was performed using Mascot (v2.4; Matrix Science, Boston, MA). Data were searched against a manually curated TrEMBL (Translated European Molecular Biology Laboratory) database containing the major genera identified in an initial search against all TrEMBL bacterial proteins. The curated database contained 57 different bacterial taxa (Supplemental Table 9) and the database from Homo sapiens to rule out potential homologs. Human peptide identity searching was performed with Mascot v2.4.0 (Matrix Science) against the human SwissProt database. A decoy database was included to determine the false discovery rate. Search results for both human and bacteria were imported into scaffold separately to validate the protein identifications, using the following criteria: $\leq$ $0.1 \%$ false discovery rate (FDR) for peptide identification, $\leq 1 \%$ FDR for protein identification, and at least 2 unique peptides identified per protein. Microbial abundance was calculated by summing normalized total spectral counts for all proteins associated with each genus. Host proteome results were imported into Progenesis LC-Mass Spectrometry software to perform label-free differential protein expression analysis based on MS peak intensities. Feature detection, normalization, and quantification were all performed using default settings from the software.

\section{Functional microbiome analysis}

Functional microbiome analysis was performed using KEGG (Kyoto Encyclopedia of Genes and Genomes) ontology assignment through the GhostKOALA (KEGG Orthology And Links Annotation) portal. Pathway maps were reconstructed using observed proteins and manually curated to remove 7 categories associated with organism-level functions (aging, cardiovascular diseases, endocrine and metabolic diseases, endocrine system, immune system, nervous system, neurodegenerative diseases), protein not found in the database, and 2 general "overview" categories to eliminate redundancy (global overview and maps, cancers: overview). Cumulative functional abundance for each category was calculated by summing abundances of all associated protein spectral counts, and proteins belonging to multiple categories contributed to each of those associated.

\section{Protein set enrichment analysis}

Pre-ranked $\log _{2}$ mean fold change difference values (neovagina vs cis vagina) were uploaded to the Broad Institute's gene set enrichment tool (http://www. broadinstitute.org/gsea), and compared against a cervical immune cell library with phenotypes defined via flow cytometry, and high vs low levels separated via median cell count. The cervical immune cells were phenotyped using the following antibodies: CD19-APC, CD56-PE-Cy7, CCR5-FITC, CD38-BUV737, CD184-BV650, CD4-APCH7, CD3-v500, CD8-BV605, HLA-DR-PE-CF594, CCR6BV711, CD49d-PE-Cy5, beta-7 integrin-BV421, CD14PerCP-Cy5.5, CD16-Alexa700, CD15-BUV395, and fixable viability stain 570 (all antibodies obtained from BD Biosciences). Samples were fixed in 1\% paraformaldehyde prior to acquisition on an LSR II (BD Biosciences). Human peripheral blood mononuclear cells were used for staining controls and fluorescence minus one controls. Data was analyzed using FlowJo v10 (Treestar).

The protein set size parameters were set between 15 and 500 proteins associated. Protein sets with an FDR $q$ value below 0.05 were included in our analysis. For protein sets with overlapping associations with our data set, only those with a normalized enrichment score greater than 2 are shown. We defined normalized enrichment scores (NES) greater than an absolute value of 2.0 as high scoring, NES $>|1.5|$ as medium scoring, and NES $<$ 1.5 as weak scoring. Enrichment scores are assigned based on how similar each protein is ranked between the two data sets. The greater the overlap and consistent ranking of proteins between our data set and the predefined data set, the higher the enrichment score. The 
rank metric score is the score used to position the gene in the ranked list and represents each protein's correlation with your phenotype of interest (i.e., neovaginal vs cis vagina).

\section{$16 \mathrm{~S}$ rRNA gene analysis}

\section{Canadian cis vaginal 16S rRNA gene analysis}

DNA extraction from $75 \mu \mathrm{L}$ of cervicovaginal lavage (CVL) was carried out in triplicate for each biological sample using the DNeasy Blood and Tissue kit (QIAGEN, Inc., Toronto, ON) with modifications to increase lysis [29]. These modifications were to mix $10 \mu \mathrm{L}$ lysozyme $(100 \mathrm{mg} / \mathrm{mL}$ stock $), 2.5 \mu \mathrm{L}$ mutanolysin $(25 \mathrm{U} / \mu \mathrm{L}$ stock), and $90 \mu \mathrm{L}$ TES buffer ( $25 \mathrm{mM}$ Tris- $\mathrm{HCl}$ (pH 8.0), $10 \mathrm{mM}$ EDTA, $10 \%(\mathrm{w} / \mathrm{v})$ sucrose) with each sample and incubate at $37^{\circ} \mathrm{C}$ for $30 \mathrm{~min}$. Next, $600 \mu \mathrm{L}$ of lysis buffer (100 mM Tris, $100 \mathrm{mM}$ EDTA, $10 \mathrm{mM} \mathrm{NaCl}, 1 \%$ SDS, $\mathrm{pH}$ 8.0) was added, followed by a 15 -min incubation at room temperature. Then, $25 \mu \mathrm{L}$ proteinase $\mathrm{K}$ and $200 \mu \mathrm{L}$ buffer AL (Qiagen) were added, and samples were incubated at $56^{\circ} \mathrm{C}$ for $30 \mathrm{~min}$. After this step, the manufacturer's protocol (Qiagen) was followed for the remainder of extraction. Mock community and water controls were processed alongside samples. DNA was amplified using $341 \mathrm{~F}$ and $785 \mathrm{R}$ primers targeting the V3-V4 region of the 16S rRNA gene [52], with overhang adaptor sequences added for sequencing [53]. Full primer sequences including this overhang were 5' -TCGTCGGCAGCGTCAGATGTGTATAAGAGAC AGCCTACGGGNGGCWGCAG-3' for the forward primer, and 5'-GTCTCGTGGGCTCGGAGATGTG TATAAGAGACAGGACTACHVGGGTATCTAATCC

-3 ' for the reverse primer. The PCR reaction was completed in a total volume of $25 \mu \mathrm{L}$, with each reaction containing $1 \mu \mathrm{L}$ of template DNA, $16.25 \mu \mathrm{L}$ UltraPure $^{\mathrm{Ta}}$ DNase/RNase-free distilled water (Thermo Fisher, Mississauga, ON), $2.5 \mu \mathrm{L}$ PCR Gold Buffer (10×), $2.5 \mu \mathrm{L} \mathrm{MgCl}_{2}(25 \mathrm{mM}), 0.5 \mu \mathrm{L}$ dNTPs $(10 \mathrm{mM})$, $1 \mu \mathrm{L}$ forward primer $(0.5 \mu \mathrm{M}), 1 \mu \mathrm{L}$ reverse primer $(0.5 \mu \mathrm{M})$, and $0.25 \mu \mathrm{L}$ AmpliTaq Gold ${ }^{\mathrm{m}}$ Taq DNA polymerase $(5 \mathrm{U} / \mu \mathrm{L})$ (Thermo Fisher, Mississauga, ON). Samples were denatured at $95^{\circ} \mathrm{C}$ for $3 \mathrm{~min}$ then underwent 35 cycles of $95^{\circ} \mathrm{C}$ for $30 \mathrm{~s}, 55^{\circ} \mathrm{C}$ for $30 \mathrm{~s}$, and $72^{\circ} \mathrm{C}$ for $30 \mathrm{~s}$, followed by a final extension at $72{ }^{\circ} \mathrm{C}$ for $5 \mathrm{~min}$.

PCR products were purified using Ampure XP beads (Beckman Coulter, Mississauga, ON) and run on QIAXcel Advanced Instrument (QIAGEN, Inc., Toronto, ON) to check amplicon purity and band size. All samples were amplified to add sequencing adaptors in a second PCR, using Nextera XT Index Kit v2 Set A and Set D (Illumina Inc., San Diego, CA, USA). This PCR reaction was completed in a total volume of $50 \mu \mathrm{L}$ and had $8 \mathrm{cy}$ cles of $95^{\circ} \mathrm{C}$ for $30 \mathrm{~s}, 55^{\circ} \mathrm{C}$ for $30 \mathrm{~s}, 72{ }^{\circ} \mathrm{C}$ for $30 \mathrm{~s}$, followed by extension at $72{ }^{\circ} \mathrm{C}$ for $5 \mathrm{~min}$. PCR products were again purified using Ampure XP beads and run on QIAXcel Advanced Instrument (QIAGEN, Inc., Toronto, $\mathrm{ON}$ ) to check amplicon purity and band size. DNA concentration in nanograms per microliter was quantified using Qubit 2.0 fluorometer (Life Technologies, Inc., Burlington, ON), after which concentration of all samples was normalized to $4 \mathrm{nM}$. Samples were prepared for MiSeq following manufacturer's protocol (Illumina Inc., San Diego, CA, USA). Final pooled DNA was diluted to $8 \mathrm{pM}$, and a spike-in of $10 \%$ PhiX was run with pooled samples. Experiment was run on Illumina MiSeq using 500 cycle v2 PE reagents, resulting in $2 \times 250$ bp pairedend reads.

Reads were analyzed using mothur v1.39.5 [54] and following outline of the MiSeq SOP [55]. Briefly, forward and reverse reads for each sample were joined into contigs and the primer sequences were trimmed. The tertiary quartile of contig length was found to be $427 \mathrm{bp}$, and therefore, any contigs over $427 \mathrm{bp}$ in length were discarded. A custom version of the 16S rDNA SILVA reference alignment (v132) [56] was made specific to the $\mathrm{V} 3-\mathrm{V} 4$ region of the $16 \mathrm{~S}$ rRNA gene, and contigs were aligned to this reference. Any sequences that did not align were discarded. Sequences with up to 2 base pair differences were combined in a precluster step, following which chimeras were identified and removed using UCHIME [57]. Sequences were then classified using the naive Bayesian classifier [58] and Ribosomal Database Project (RDP) taxonomy database (v16) [59]. Phylotype classification was used to identify sequences to the phylogenetic level of genus, and a taxonomy summary table produced.

Sixty-two genera were identified across all samples. Taxa that were identified with a higher abundance in water controls than in samples (based on a fold calculation) were removed as contaminants, with the exception of Pseudomonas. This taxon was detected at a similar level of low abundance in both samples and water control, but as we have previously detected Pseudomonas in CVL samples using mass spectrometry, we elected to include this genus [10]. Replicates for each biological sample were pooled, and for the purposes of visualization, the top $25 \%$ most abundant taxa overall are shown, while remaining lower abundance taxa have been binned to "other."

\section{Swedish cis vaginal $16 \mathrm{~S}$ rRNA gene analysis}

DNA extraction, targeted amplification, and sequencing of the V3-V4 regions of the 16S rRNA gene from vaginal mucosal samples were performed as described previously [60].

TW neovaginal and rectal mucosal 16S rRNA gene analysis DNA extraction, targeted amplification, and sequencing of the V4 region of the $16 \mathrm{~S}$ rRNA gene were performed 
as previously described [61]. Sequences were demultiplexed with Golay error correction using QIIME 1.9.1. Divisive amplicon denoising algorithm version 2 (DADA2) was used for error correction, exact sequence inference, and chimera removal [62]. Taxonomic assignment was performed using the RDP classifier with trainset 16 (https://doi.org/10.5281/zenodo.801827).

\section{Statistical analysis}

Differential protein expression was performed using non-parametric Mann-Whitney $U$ tests. Power calculations were performed in $G$ *Power (v3.1.9.2). We were able to detect host proteome differences of 2.7 -fold between samples taken from cis vaginas $(n=30)$ and neovaginas $(n=5)$ while retaining $80 \%$ power, assuming a proteome variance of $100 \%$ [60], an adjusted alpha = 0.0001. Alpha (Shannon's $H$ index) and beta diversity (Bray-Curtis dissimilarity distances) calculations as well as permutational multivariate analysis of variance (perMANOVA) calculations were performed in $\mathrm{R}$ (v3.5.0) using the vegan.R (v2.5-3) package. Principal coordinate analysis was conducted in $\mathrm{R}$ using ape. $\mathrm{R}$ (v5.2) package. The phyloseq.R (v1.16) package was also used for the analysis of $16 \mathrm{~S}$ microbiome profiling data. Principal component analysis was conducted in MatLab and EigenVector software. Graphs and statistical analysis for bacterial protein function were generated using the functional microbiome analysis pipeline (LOGAN) [63]. Hierarchical clustering was conducted in R using NMF.R (v0.21.0). Pearson distance metrics and complete linkage were the parameters specified. Human protein functional analysis was conducted using over-representation analysis via ConsensusPathDB (Max Planck Institute for Molecular Genetics). Pathway-based sets (INOH, Reactome, KEGG) and gene ontology biological processes level 5 categories were selected. $p$ values were calculated using hypergeometric tests.

\section{Supplementary information}

Supplementary information accompanies this paper at https://doi.org/10. 1186/s40168-020-00804-1.

\section{Additional file 1: Supplemental Figure 1. Microbial profiles of} neovaginal secretions from transgender women. A) Microbial profiles as measured via $16 \mathrm{~S}$ rRNA gene sequencing. B) Microbial profiles as measured via metaproteomics. NV6 had the penile inversion/scrotal graft surgical method with sigmoid colon graft extension, while the other neovaginas (NV1, NV2, NV4, and NV7) were penile inversion/scrotal graft method only.

Additional file 2: Supplemental Figure 2. Microbial profiles of vaginal secretions from cis women. A) Microbial profiles of Swedish cisgender women (CW) as measured via 16S rRNA gene sequencing. B) Microbial profiles of Swedish CW as measured via metaproteomics. C) Microbial profiles of Canadian CW as measured via 16S rRNA gene sequencing. D) Microbial profiles of Canadian CW as measured via metaproteomics.

Additional file 3: Supplemental Figure 3. Microbial profiles of rectal secretions from transgender women. A) Microbial profiles as measured via $16 \mathrm{~S}$ rRNA gene sequencing. B) Microbial profiles as measured via metaproteomics.

Additional file 4: Supplemental Figure 4. Matched neovaginal and rectal samples show limited bacterial composition similarity. A) Bacterial composition profiles measured via metaprotemics. Microbial abundance was calculated by summing normalized total spectral counts for all proteins associated with each genus. B) Prinicipal coordinate analysis (PCoA) plots of Bray-Curtis distance of microbial composition. The composition was driven by sample type and Roseburia levels. Each dot represents one individual sample. (NV=neovaginal, $R=$ =rectal).

Additional file 5: Supplemental Figure 5. The functional profiles of cis vaginal and neovaginal samples based on bacterial proteins measured by mass spectrometry and functions assigned through the KEGG pathways database.

Additional file 6: Supplemental Figure 6. Protein set enrichment analysis identifies overlapping signatures measured in the neovagina of transgender women and in cervices of cisgender women with elevated activated CD4+ T cell levels. A) Pre-ranked proteins are plotted based on their enrichment score. Each dot on the plot represents overlapping proteins known to decrease in individuals with elevated cervical

CD4+CD38+HLADR+ T cell levels as well as those known to decrease in neovagina relative to cis vagina. B) The rank metric score represents each protein's correlation with the neovaginal phenotype. Proteins highlighted in blue represent those that account for the core enrichment, proteins that contribute most to the enrichment, observed.

Additional file 7: Supplemental Table 1. Percent coverage and mean normalized bacterial spectral counts of KEGG ko level functions from neovaginal and cis vaginal compartments. Supplemental Table 2. Proteins differentially abundant between neovaginas and cis vaginas. Supplemental Table 3. Enriched host pathways positively associated with the neovaginal compartment compared to the cis vaginal compartment. Supplemental Table 4. Enriched host pathways negatively associated with the neovaginal compartment compared to the cis vaginal compartment. Supplemental Table 5. Human protein correlates of bacterial diversity as measured by Shannon's $\mathrm{H}$ index. Supplemental Table 6. Enriched host pathways positively associated with bacterial diversity as measured by Shannon's H index.

Supplemental Table 7. Enriched host pathways negatively associated with bacterial diversity as measured by Shannon's $\mathrm{H}$ index.

Supplemental Table 8. Immune cell protein set signatures that overlap with signatures enriched in the neovagina. Supplemental Table 9. Taxa included in the curated database and each taxa's protein detection from initial TREMBL bacteria database search.

\section{Abbreviations}

BV: Bacterial vaginosis; C6: Complement component 6; CAMP: Cathelicidin antimicrobial peptide; CFH: Complement factor H; CRISP3: Cysteine-rich secretory protein 3; CST: Community state type; CW: Cisgender women; FDR: False discovery rate; GRS: Gender reassignment surgery; KEGG: Kyoto Encyclopedia of Genes and Genomes; KOALA: KEGG Orthology And Links Annotation; LC: Liquid chromatography; LD: Lactobacillus dominant; MS: Mass spectrometer; NES: Normalized enrichment score; nLD: NonLactobacillus dominant; PCoA: Principal coordinate analysis; perMANOVA: Permutational multivariate analysis of variance; QSOX1: Sulfhydryl oxidase 1; STI: Sexually transmitted infection; TLR: Toll-like receptor; TREMBL: Translated European Molecular Biology Laboratory Nucleotide Sequence Database; genome mapping software; TW: Transgender women; TXN: Thioredoxin

\section{Acknowledgements}

Thank you to Stuart McCorrister and Garrett Westmacott at the Mass Spectrometry Core Facility at the National Microbiology Laboratory in Canada for technical support. Thank you to Natalie Knox and Jessica Forbes with their assistance with $16 \mathrm{~S}$ rRNA data analysis.

\section{Authors' contributions}

KDB and KK wrote the manuscript and analyzed and interpreted the data. $M A$ and KK performed the proteomic experiments. $F L$ and CY performed the 
$16 \mathrm{~S}$ analysis and analyzed data from the transwomen cohort. AL performed the $16 \mathrm{~S}$ analysis and analyzed data from the cis women cohort. CFZ generated the cervical cell database used for protein set enrichment analysis. SM and LNR generated the application for functional metaproteome analysis (LOGAN). LNR also assisted with data processing and provided statistical support. EMJ, BG, RKF, and W collected the TW's samples. KB and FB collected samples from the Swedish participant controls included in our study. VP collected samples from the Canadian participant controls included in our study. AB and GA funded and conceived the study. The authors read and approved the final manuscript.

\section{Funding}

Funding for this project was provided by the Canadian Institutes of Health Research (A.B. TMl-138658), Fiocruz PMA (Programa de Politicas Publicas e Modelos de Atencao a Saude), and the National Institutes of Health: National Institute of Allergy and Infectious Diseases (grant no: 5RO1Al128796). Overall support for the International Maternal Pediatric Adolescent AIDS Clinical Trials Group (IMPAACT) was provided by the National Institute of Allergy and Infectious Diseases (NIAID) of the National Institutes of Health (NIH) under award numbers UM1AI068632 (IMPAACT LOC), UM1AI068616 (IMPAACT SDMC), and UM1AI106716 (IMPAACT LC), with co-funding from the Eunice Kennedy Shriver National Institute of Child Health and Human Development (NICHD) and the National Institute of Mental Health (NIMH). The content is solely the responsibility of the authors and does not necessarily represent the official views of the $\mathrm{NIH}$.

\section{Availability of data and materials}

16S rRNA gene sequence files and metadata for the TW and CW samples used in this study have been deposited in Figshare (https://figshare.com/ articles/TW_neovaginal_rectal_buccal_seq/11690382; https://figshare.com/ articles/CW_16S/11710227). Data sets including unrarefied OTU tables from $16 \mathrm{~S}$ rRNA gene sequence data, metadata, protein spectral count data, and $\mathrm{R}$ scripts used in this study are available in GitHub (https://github.com/ kmbirse/Birse_etal_Neovaginal-Microbiome).

\section{Ethics approval and consent to participate}

The study was approved by the Research Ethics Committee at the Evandro Chagas National Institute of Infectology (Rio de Janeiro, Brazil, CAAE: 55081016.0.0000.5262), the Research Ethics Board of the University of Manitoba (ethics \#HS21185 (H2017:338)), and the Stocholm Regional Ethics Board (2018/1476-32/2). Written informed consent was obtained from all study participants.

\section{Consent for publication}

$$
\text { Not applicable }
$$

\section{Competing interests}

The authors declare that they have no competing interests.

\section{Author details}

${ }^{1}$ National HIV and Retrovirology Labs, JC Wilt Infectious Disease Research Centre, Public Health Agency of Canada, 745 Logan Ave, Winnipeg, MB R3E 3 L5, Canada. ${ }^{2}$ Departments of Medical Microbiology and Infectious Disease, University of Manitoba, Winnipeg, MB, Canada. ${ }^{3}$ Instituto Nacional de Infectologia Evandro Chagas, Rio de Janeiro, Brazil. ${ }^{4}$ Department of Medicine Solna, Center for Molecular Medicine, Unit of Infectious Diseases, Karolinska Institutet, Karolinska University Hospital, Stockholm, Sweden. ${ }^{5}$ Department of Obstetrics \& Gynecology, University of Manitoba, Winnipeg, MB, Canada. ${ }^{6}$ University of California, Los Angeles, CA, USA.

Received: 19 September 2019 Accepted: 10 February 2020 Published online: 05 May 2020

\section{References}

1. Baral SD, Poteat T, Stromdahl S, Wirtz AL, Guadamuz TE, Beyrer C. Worldwide burden of HIV in transgender women: a systematic review and meta-analysis. Lancet Infect Dis. 2013;13:214-22.

2. Weinforth G, Fakin R, Giovanoli P, Nunez DG. Quality of life following maleto-female sex reassignment surgery. Dtsch Arztebl Int. 2019;116:253-60.

3. Dreher PC, Edwards D, Hager S, Dennis M, Belkoff A, Mora J, et al. Complications of the neovagina in male-to-female transgender surgery: a systematic review and meta-analysis with discussion of management. Clin Anat. 2018:31:191-9.

4. Gosmann C, Anahtar MN, Handley SA, Farcasanu M, Abu-Ali G, Bowman BA, et al. Lactobacillus-deficient cervicovaginal bacterial communities are associated with increased HIV acquisition in young South African women. Immunity. 2017:46:29-37.

5. Anahtar MN, Byrne EH, Doherty KE, Bowman BA, Yamamoto HS, Soumillon $\mathrm{M}$, et al. Cervicovaginal bacteria are a major modulator of host inflammatory responses in the female genital tract. Immunity. 2015;42:96576.

6. Eastment MC, McClelland RS. Vaginal microbiota and susceptibility to HIV. AIDS. 2018;32:687-98.

7. Liu CM, Prodger JL, Tobian AAR, Abraham AG, Kigozi G, Hungate BA, et al. Penile anaerobic dysbiosis as a risk factor for HIV infection. MBio. 2017;8.

8. Weyers S, Verstraelen H, Gerris J, Monstrey S, Santiago Gdos S, Saerens B, et al. Microflora of the penile skin-lined neovagina of transsexual women. BMC Microbiol. 2009;9:102.

9. Petricevic L, Kaufmann U, Domig KJ, Kraler M, Marschalek J, Kneifel W, et al. Rectal Lactobacillus species and their influence on the vaginal microflora: a model of male-to-female transsexual women. J Sex Med. 2014;11:2738-43.

10. Klatt NR, Cheu R, Birse K, Zevin AS, Perner M, Noel-Romas L, et al. Vaginal bacteria modify HIV tenofovir microbicide efficacy in African women. Science. 2017:356:938-45.

11. Weyers S, Lambein K, Sturtewagen Y, Verstraelen H, Gerris J, Praet M. Cytology of the 'penile' neovagina in transsexual women. Cytopathology. 2010;21:111-5.

12. Kaufmann U, Domig KJ, Lippitsch Cl, Kraler M, Marschalek J, Kneifel W, et al. Ability of an orally administered lactobacilli preparation to improve the quality of the neovaginal microflora in male to female transsexual women. Eur J Obstet Gynecol Reprod Biol. 2014;172:102-5.

13. Price LB, Liu CM, Johnson KE, Aziz M, Lau MK, Bowers J, et al. The effects of circumcision on the penis microbiome. PLoS One. 2010;5:e8422.

14. Liu CM, Hungate BA, Tobian AA, Ravel J, Prodger JL, Serwadda D, et al. Penile microbiota and female partner bacterial vaginosis in Rakai, Uganda. mBio. 2015;6:e00589.

15. Liu CM, Hungate BA, Tobian AA, Serwadda D, Ravel J, Lester R, et al. Male circumcision significantly reduces prevalence and load of genital anaerobic bacteria. mBio. 2013:4:e00076.

16. Ahmad MM. IUDs and actinomyces. IPPF Med Bull. 1987;21:3-4

17. Camelo-Castillo A, Novoa L, Balsa-Castro C, Blanco J, Mira A, Tomas I. Relationship between periodontitis-associated subgingival microbiota and clinical inflammation by 165 pyrosequencing. J Clin Periodontol. 2015;42: 1074-82.

18. Siqueira JF Jr, Rocas IN. Pseudoramibacter alactolyticus in primary endodontic infections. J Endod. 2003;29:735-8.

19. Basic A, Enerback H, Waldenstrom S, Ostgard E, Suksuart N, Dahlen G. Presence of Helicobacter pylori and Campylobacter ureolyticus in the oral cavity of a Northern Thailand population that experiences stomach pain. $J$ Oral Microbiol. 2018;10:1527655.

20. Gholizadeh P, Eslami H, Yousefi M, Asgharzadeh M, Aghazadeh M, Kafil HS Role of oral microbiome on oral cancers, a review. Biomed Pharmacother. 2016;84:552-8.

21. Vielkind $P$, Jentsch $H$, Eschrich $K$, Rodloff AC, Stingu CS. Prevalence of Actinomyces spp. in patients with chronic periodontitis. Int J Med Microbiol. 2015;305:682-8.

22. Marchandin H, Damay A, Roudiere L, Teyssier C, Zorgniotti I, Dechaud H, et al. Phylogeny, diversity and host specialization in the phylum Synergistetes with emphasis on strains and clones of human origin. Res Microbiol. 2010;161:91-100.

23. Jumas-Bilak E, Carlier JP, Jean-Pierre H, Citron D, Bernard K, Damay A, et al. Jonquetella anthropi gen. nov., sp. nov., the first member of the candidate phylum 'Synergistetes' isolated from man. Int J Syst Evol Microbiol. 2007;57: 2743-8.

24. Pescatore NA, Pollak R, Kraft CS, Mulle JG, Kelley CF. Short communication: anatomic site of sampling and the rectal mucosal microbiota in HIV negative men who have sex with men engaging in condomless receptive anal intercourse. AIDS Res Hum Retroviruses. 2018;34:277-81.

25. Haaland RE, Fountain J, Hu Y, Holder A, Dinh C, Hall L, et al. Repeated rectal application of a hyperosmolar lubricant is associated with microbiota shifts but does not affect PrEP drug concentrations: results from a randomized trial in men who have sex with men. J Int AIDS Soc. 2018;21:e25199. 
26. Smith BC, Zolnik CP, Usyk M, Chen Z, Kaiser K, Nucci-Sack A, et al. Distinct ecological niche of anal, oral, and cervical mucosal microbiomes in adolescent women. Yale J Biol Med. 2016;89:277-84.

27. Petrina MAB, Cosentino LA, Rabe LK, Hillier SL. Susceptibility of bacterial vaginosis (BV)-associated bacteria to secnidazole compared to metronidazole, tinidazole and clindamycin. Anaerobe. 2017:47:115-9.

28. Srinivasan S, Morgan MT, Fiedler TL, Djukovic D, Hoffman NG, Raftery D, et al. Metabolic signatures of bacterial vaginosis. MBio. 2015;6

29. Zevin AS, Xie IY, Birse K, Arnold K, Romas L, Westmacott G, et al. Microbiome composition and function drives wound-healing impairment in the female genital tract. PLoS Pathog. 2016;12:e1005889.

30. Borgdorff H, Gautam R, Armstrong SD, Xia D, Ndayisaba GF, van Teijlingen $\mathrm{NH}$, et al. Cervicovaginal microbiome dysbiosis is associated with proteome changes related to alterations of the cervicovaginal mucosal barrier. Mucosal Immunol. 2016;9:621-33.

31. Dang AT, Teles RM, Liu PT, Choi A, Legaspi A, Sarno EN, et al. Autophagy links antimicrobial activity with antigen presentation in Langerhans cells. JC Insight. 2019;4

32. Bandurska K, Berdowska A, Barczynska-Felusiak R, Krupa P. Unique features of human cathelicidin LL-37. Biofactors. 2015;41:289-300.

33. Moschen AR, Gerner RR, Wang J, Klepsch V, Adolph TE, Reider SJ, et al Lipocalin 2 protects from inflammation and tumorigenesis associated with gut microbiota alterations. Cell Host Microbe. 2016;19:455-69.

34. Gu C, Mao X, Chen D, Yu B, Yang Q. Isoleucine plays an important role for maintaining immune function. Curr Protein Pept Sci. 2019.

35. Zhou H, Yu B, Gao J, Htoo JK, Chen D. Regulation of intestinal health by branched-chain amino acids. Anim Sci J. 2018;89:3-11.

36. Ravindran R, Loebbermann J, Nakaya HI, Khan N, Ma H, Gama L, et al. The amino acid sensor GCN2 controls gut inflammation by inhibiting inflammasome activation. Nature. 2016;531:523-7.

37. Stieh DJ, Matias E, Xu H, Fought AJ, Blanchard JL, Marx PA, et al. Th17 cells are preferentially infected very early after vaginal transmission of SIV in macaques. Cell Host Microbe. 2016;19:529-40.

38. Ueland PM, McCann A, Midttun O, Ulvik A. Inflammation, vitamin B6 and related pathways. Mol Aspects Med. 2017;53:10-27.

39. Qian B, Shen S, Zhang J, Jing P. Effects of vitamin B6 deficiency on the composition and functional potential of T cell populations. J Immunol Res. 2017;2017:2197975.

40. Qiao L, Rodriguez E Jr, Weiss DA, Ferretti M, Risbridger G, Cunha GR, et al. Expression of estrogen receptor alpha and beta is decreased in hypospadias. J Urol. 2012;187:1427-33.

41. Reed HM, Yanes RE, Delto JC, Omarzai Y, Imperatore K. Non-grafted vaginal depth augmentation for transgender atresia, our experience and survey of related procedures. Aesthetic Plast Surg. 2015;39:733-44.

42. Delva E, Tucker DK, Kowalczyk AP. The desmosome. Cold Spring Harb Perspect Biol. 2009;1:a002543.

43. Rotzer V, Hartlieb E, Winkler J, Walter E, Schlipp A, Sardy M, et al. Desmoglein 3-dependent signaling regulates keratinocyte migration and wound healing. J Invest Dermatol. 2016;136:301-10.

44. Takeda M, Nomura T, Sugiyama T, Miyauchi T, Suzuki S, Fujita Y, et al. Compound heterozygous missense mutations p.Leu207Pro and $p$. Tyr544Cys in TGM1 cause a severe form of lamellar ichthyosis. J Dermatol. 2018:45:1463-7.

45. Charles CA, Tomic-Canic M, Vincek V, Nassiri M, Stojadinovic O, Eaglstein $\mathrm{WH}$, et al. A gene signature of nonhealing venous ulcers: potential diagnostic markers. J Am Acad Dermatol. 2008;59:758-71.

46. Li S, Herrera GG, Tam KK, Lizarraga JS, Beedle MT, Winuthayanon W. Estrogen action in the epithelial cells of the mouse vagina regulates neutrophil infiltration and vaginal tissue integrity. Sci Rep. 2018;8:11247.

47. Miyagawa S, Iguchi T. Epithelial estrogen receptor 1 intrinsically mediates squamous differentiation in the mouse vagina. Proc Natl Acad Sci U S A. 2015:112:12986-91.

48. Pask AJ, Mclnnes KJ, Webb DR, Short RV. Topical oestrogen keratinises the human foreskin and may help prevent HIV infection. PLoS One. 2008;3: e2308.

49. Mills RH, Vazquez-Baeza Y, Zhu Q, Jiang L, Gaffney J, Humphrey G, et al. Evaluating metagenomic prediction of the metaproteome in a 4.5 -year study of a patient with Crohn's disease. mSystems. 2019;4.

50. Kleiner M, Thorson E, Sharp CE, Dong X, Liu D, Li C, et al. Assessing species biomass contributions in microbial communities via metaproteomics. Nat Commun. 2017:8:1558
51. Zhou J, He Z, Yang Y, Deng Y, Tringe SG, Alvarez-Cohen L. High-throughput metagenomic technologies for complex microbial community analysis: open and closed formats. mBio. 2015;6.

52. Klindworth A, Pruesse E, Schweer T, Peplies J, Quast C, Horn M, et al. Evaluation of general 165 ribosomal RNA gene PCR primers for classical and nextgeneration sequencing-based diversity studies. Nucleic Acids Res. 2013;41:e1.

53. Illumina. 165 metagenomic sequencing library preparation. In: Preparing 165 Ribosomal RNA Gene Amplicons for the Illumina MiSeq System: Illumina; 2013.

54. Schloss PD, Westcott SL, Ryabin T, Hall JR, Hartmann M, Hollister EB, et al. Introducing mothur: open-source, platform-independent, communitysupported software for describing and comparing microbial communities. Appl Environ Microbiol. 2009;75:7537-41.

55. Kozich JJ, Westcott SL, Baxter NT, Highlander SK, Schloss PD. Development of a dual-index sequencing strategy and curation pipeline for analyzing amplicon sequence data on the MiSeq Illumina sequencing platform. Appl Environ Microbiol. 2013;79:5112-20.

56. Pruesse E, Quast C, Knittel K, Fuchs BM, Ludwig W, Peplies J, et al. SILVA: a comprehensive online resource for quality checked and aligned ribosomal RNA sequence data compatible with ARB. Nucleic Acids Res. 2007;35:7188-96.

57. Edgar RC, Haas BJ, Clemente JC, Quince C, Knight R. UCHIME improves sensitivity and speed of chimera detection. Bioinformatics. 2011;27:2194-200.

58. Wang Q, Garrity GM, Tiedje JM, Cole JR. Naive Bayesian classifier for rapid assignment of rRNA sequences into the new bacterial taxonomy. Appl Environ Microbiol. 2007:73:5261-7.

59. Cole JR, Wang Q, Cardenas E, Fish J, Chai B, Farris RJ, et al. The Ribosomal Database Project: improved alignments and new tools for rRNA analysis. Nucleic Acids Res. 2009;37:D141-5.

60. Bradley F, Birse K, Hasselrot K, Noel-Romas L, Introini A, Wefer H, et al. The vaginal microbiome amplifies sex hormone-associated cyclic changes in cervicovaginal inflammation and epithelial barrier disruption. Am J Reprod Immunol. 2018:80:e12863.

61. Tobin NH, Woodward C, Zabih S, Lee DJ, Li F, Aldrovandi GM. A method for targeted 16S sequencing of human milk samples. J Vis Exp. 2018.

62. Callahan BJ, McMurdie PJ, Rosen MJ, Han AW, Johnson AJ, Holmes SP. DADA2: High-resolution sample inference from Illumina amplicon data. Nat Methods. 2016;13:581-3.

63. PM MS, Birse K, Schellenberg J, Lauffenburger D, Noel-Romas L, Burgener A. Cohort-level analysis of the functional variation of the vaginal microbiome. In: HIV Research for Prevention. Madrid: Mary Ann Liebert, Inc Publishers; 2018.

64. Birse K, Arnold KB, Novak RM, McCorrister S, Shaw S, Westmacott GR et al. Molecular signature of immune activation and epithelial barrier remodeling are enhanced during the luteal phase of the menstrual cycle: implications for HIV susceptibility. J Virol. 2015;89:8793-805.

\section{Publisher's Note}

Springer Nature remains neutral with regard to jurisdictional claims in published maps and institutional affiliations.

Ready to submit your research? Choose BMC and benefit from:

- fast, convenient online submission

- thorough peer review by experienced researchers in your field

- rapid publication on acceptance

- support for research data, including large and complex data types

- gold Open Access which fosters wider collaboration and increased citations

- maximum visibility for your research: over $100 \mathrm{M}$ website views per year

At $\mathrm{BMC}$, research is always in progress.

Learn more biomedcentral.com/submission 